\title{
Representações de alunos surdos sobre a inclusão nas aulas de educação física
}

\author{
Tássia Pereira Alves* \\ Zenilda Nogueira Sales** \\ Ramon Missias Moreira*** \\ Leonardo de Carvalho Duarte**** \\ Riane Missias Moreira Mendes Souza*****
}

\section{Resumo}

A inclusão é um processo social que, no contexto escolar, pretende a mudança de atitudes e a construção de uma postura com condições de abranger a todos indistintamente. Destarte, objetivou-se analisar as representações de alunos surdos sobre sua inclusão nas aulas de Educação Física. Trata-se de pesquisa qualitativa, descritiva e analítica, na qual participaram todos os alunos surdos, totalizando 8, de 2 escolas públicas de um município do interior da Bahia. Para produção de dados, utilizou-se a entrevista semiestruturada, através do auxílio do intérprete da língua brasileira de sinais (LIBRAS), que, ao mesmo tempo, foram traduzidas pelo intérprete e transcritas pelos pesquisadores. Para análise dos dados utilizou-se a técnica de análise de conteúdo categorial. A inclusão dos surdos nas aulas de Educação Física ainda não se efetivou, mesmo tendo encontrado alguns professores com ações pedagógicas que demonstraram serem inclusivas, contudo, elas ainda deixam várias lacunas no que diz respeito a uma aprendizagem satisfatória dos alunos. Não basta apenas integrar o aluno surdo em sala de aula, é preciso que a escola e o professor garantam que os conteúdos curriculares sejam acessíveis a eles, de modo que possam contribuir na construção da cidadania, no desenvolvimento motor, cognitivo e social-afetivo desses alunos.

Palavras-chave: Inclusão; Surdos; Educação Física.

\footnotetext{
* Graduada em Educação Física pela Universidade Estadual do Sudoeste da Bahia Jequié, Bahia, Brasil.

** Professora Doutara em Enfermagem pela Universidade Federal do Ceará, Forteleza, Ceará, Brasil.

*** Mestre em Enfermagem e Saúde pela Universidade Estadual do Sudoeste da Bahia, Jequié, Bahia, Brasil.

**** Mestre em Educação pela Universidade Federal da Bahia, Salvador, Bahia, Brasil.

***** Acadêmica do Curso de Licenciatura em Pedagogia pela Universidade Estadual do Sudoeste da Bahia, Jequié, Bahia, Brasil
} 


\section{Representations of deaf students about inclusion in physical education classes}

\section{Abstract}

Inclusion is a social process in school aims to change attitudes and to build a position to cover everyone without distinction. Thus, the objective was to analyze the representations of deaf students on their inclusion in physical education classes. It is qualitative, descriptive and analytical, attended eight deaf students from 2 public schools in a city in the countryside of Bahia. For data production, it was used a semi -structured interview, through the aid of an interpreter of Brazilian Sign Language (Libras), at the same time, it was translated by the interpreter and transcribed by the researchers. Data analysis used the technique of categorical content analysis. The inclusion of deaf people in physical education classes still failed to materialize and in fact, even having found some teachers with pedagogical actions that proved to be inclusive, yet they still leave many gaps, regarding satisfactory learning of students because they simply just integrate deaf students in the classroom. It is necessary that the school and the teacher ensure that the curriculum is accessible to them, so that they can contribute to the construction of citizenship, motor development, cognitive and social-emotional student.

Keywords: Inclusion; Deaf; Physical education.

\section{Introdução}

A educação inclusiva é um processo social que vem se desenvolvendo em todo o mundo e direciona os pensamentos para a reflexão sobre a educação e o papel da escola nos tempos hodiernos. Portanto, compreende-se que a educação escolar deve proporcionar a todos os indivíduos o desenvolvimento social, cognitivo, psicológico e afetivo, de maneira integral, preparando-os para exercerem suas capacidades e funções de modo pleno na sociedade (NOZI; VITALIANO, 2012).

A eliminação das barreiras existentes é complexa, devendo ser um processo contínuo de conscientização e sensibilização da sociedade no sentido de acolher todas as pessoas independentemente das suas diferenças individuais e de suas origens. Nesse contexto, a constituição de uma Educação Inclusiva já se tornou uma exigência nas escolas do Brasil, seja por uma ordem legal, por conta das políticas públicas, ou mesmo por uma pressão cada vez mais organizada de grupos sociais ligados à questão das pessoas com deficiência.

Deste modo, a disciplina Educação Física como parte integrante da grade curricular das escolas não poderia ausentar-se desse processo de inclusão, por se tratar de uma área do conhecimento que pode contribuir significativamente para o desenvolvimento biopsicomotor dos alunos. 
Nessa perspectiva, sabendo-se que as aulas de Educação Física sempre estiveram ligadas a cultura do desempenho, performance e competição, através dos esportes, como pensar na inclusão de alunos com deficiência estando eles fora dos padrões exigidos para as práticas corporais? Ao pensar na inclusão de pessoas com deficiência na Educação Física Escolar, muitos podem pensar que é algo impossível, pois, as pessoas, ao verem um deficiente, enxergam apenas a deficiência caracterizando-o como um indivíduo incapaz (RECHINELI; PORTO; MOREIRA, 2008).

Em se tratando da surdez, corrobora-se com Greguol (2010), ao argumentar que, apesar da deficiência auditiva aparentemente não demonstrar grandes comprometimentos ao desenvolvimento geral do indivíduo, o impacto da perda do sentido da audição pode acarretar em sérios danos e agravos, caso o indivíduo não tenha estímulos apropriados. Segundo Dizeu e Caporali (2005), o contato da criança surda, desde os primeiros anos de idade, com adultos surdos possibilitará que esta criança consiga entender o mundo em que vive, o que ajuda na construção da sua subjetividade.

Este estudo torna-se ainda mais relevante, pois falar de inclusão numa sociedade excludente, desigual, com estigmas e paradigmas é uma tarefa árdua e difícil, principalmente, no que concerne a Educação Física Escolar tendo em vista que seu passado, não muito distante, apresentou um compromisso maior com a eficiência do que com a cooperação e o desenvolvimento integral dos alunos. Entretanto, cabe salientar que as diferenças socioeconômicas podem interferir diretamente no processo de inclusão, tendo em vista que, possivelmente, crianças e adolescentes com deficiência que estejam inseridos na classe média ou média alta possam ter acesso a um número maior de atividades físico-esportivas compatíveis com suas necessidades reais.

Nesse contexto, refletir sobre a educação de surdos requer ir além das propostas educacionais, pois os que são diferentes, no sentido de não se enquadrem no que é esperado e determinado socialmente, não são reconhecidos como um produto do meio sociocultural, sendo limitados à sua diferença (VILELA-RIBEIRO; BENITE; VILELA, 2013). Porém, deve-se oportunizar estes indivíduos como cidadãos que têm todos os direitos de atuar na sociedade com as mesmas oportunidades as quais são conferidas aos ouvintes.

Diante do exposto, a pesquisa objetivou analisar as representações de alunos surdos sobre sua inclusão nas aulas de Educação Física Escolar.

\section{Método}

De acordo com Santos Filho e Gamboa (2007), a pesquisa desenvolvida em todas as dimensões do campo educacional e seus diversos objetos de pesquisa requerem métodos que se adequem à natureza do problema pesquisado. Considerando a especificidade da problemática apresentada, esse estudo se insere no campo da pesquisa qualitativa, em função da necessidade de discutir e melhor qualificar os elementos que envolvem o objeto de estudo, por já ter evidenciado efeitos no tratamento de questões educacionais. 
Trata-se de uma pesquisa com caráter descritivo, tendo como particularidade, observar, analisar, descrever e correlacionar fatos ou fenômenos sem manipulá -los, tentando encontrar a constância nos acontecimentos e se estes estabelecem uma relação (MATTOS; ROSSETTO JUNIOR; BLECHER, 2008).

O estudo foi desenvolvido em duas escolas públicas de um município do interior da Bahia, uma municipal e outra estadual, por serem as duas maiores escolas do município que atendem à comunidade de surdos. Participaram dessa investigação todos os alunos surdos, totalizando oito entrevistados, matriculados e com frequência regular.

Para produção de dados, optamos pela entrevista semiestruturada, a partir de questões norteadoras relacionadas diretamente com o objeto desse estudo. A entrevista foi aplicada mediante a presença de um intérprete da Língua Brasileira de Sinais (LIBRAS), responsável por auxiliar na tradução e transmissão dos conteúdos das disciplinas curriculares para os alunos surdos, inclusive nas aulas de Educação Física. Cada entrevista teve duração de aproximadamente 40 minutos, e o período de coleta de dados foi entre os meses de Abril e Maio de 2012.

Os dados oriundos das entrevistas foram organizados, tratados, e analisados a luz da Técnica de Análise de Conteúdo Temática Categorial, proposta por Bardin (2011), e obedecendo aos seguintes passos: $1^{a}$ FASE: pré-análise, $2^{2}$ FASE: exploração do material e $3^{\underline{a}}$ FASE: tratamento dos dados, inferência e interpretação.

Quanto ao processamento das falas dos sujeitos e para facilitar a compreensão acerca dessas informações e do significado de cada eixo temático que emergiu das representações dos sujeitos, os resultados serão apresentados por categorias de análise. Essas categorias são discutidas tomando-se como princípio de análise a interpretação das unidades de análise temáticas (BARDIN, 2011). Ao final de cada recorte realizado nas falas dos sujeitos, será indicado entre parênteses a identificação a partir das siglas $\mathrm{Al}$ à $\mathrm{A} 8$.

Dessa forma, buscando atender os preceitos da ética em pesquisa, o estudo respeitou os aspectos éticos preconizados na Resolução n. 196/96 do Conselho Nacional de Saúde, onde a coleta foi iniciada após assinatura do Termo de Consentimento Livre e Esclarecido pelos adolescentes e pelos pais ou responsáveis, quando se tratava de informantes menores de idade.

\section{Resultados e discussão}

Embora não seja objetivo desse estudo, consideramos relevante destacar algumas características dos entrevistados, na tentativa de oportunizar conhecimento acerca do grupo de pertença que foi objeto dessa investigação. Verifica-se que participaram 08 alunos surdos, destes, seis eram do sexo feminino. Em relação a idade, houve variação entre 15 e 22 anos de idade, sendo que a maior incidência foi de adolescentes 
com 16 anos de idade. Do total de entrevistados três estavam cursando o $2^{\circ}$ e $3^{\circ}$ ano do ensino médio e cinco estavam entre o $6^{\circ}$ e $7^{\circ}$ ano do ensino fundamental.

Nesse sentido, a partir da análise dos conteúdos manifestos, de onde emergiram os núcleos de sentido, surgindo quatro categorias referentes às percepções dos alunos surdos sobre sua inclusão nas aulas de Educação Física. Desse modo, encontram-se na seguinte ordem sequencial: participação nas aulas de Educação Física; inclusão nas aulas de Educação Física; percepção dos alunos sobre as aulas de Educação Física; e comunicação durante as aulas.

\section{Participação nas aulas de Educação Física}

Os professores de Educação Física devem utilizar seus conhecimentos para garantir a todos os seus alunos, deficientes auditivos ou não, aulas motivadoras, interessantes e de qualidade, demonstrando o quanto se pode contribuir culturalmente, socialmente, cognitivamente e fisicamente na formação desses alunos, abarcando, dessa maneira, uma maior e efetiva participação dos sujeitos nas suas aulas.

A partir da análise dos depoimentos dos informantes desta pesquisa, observamos, nas unidades de análise que sustentam a categoria Participação nas aulas de Educação Física

[...] Participo por obrigação, para ter nota nas unidades, sempre perdia nos jogos para não continuar na atividade. Não acho interessante a prática e sim a teoria principalmente em relação ao corpo humano. (Al)

[...] só estudo a disciplina porque faz parte das minhas disciplinas: entrava por um ouvido e saia por outro. (A2)

[...] Na maioria das vezes participo das aulas teóricas. Tenho preguiça [...] (A4)

Verificamos, nesses recortes, que a participação dos alunos surdos nas aulas de Educação Física deve-se, principalmente, pelas seguintes questões: obrigatoriedade das aulas, preferência pelas aulas teóricas, desinteresse e desmotivação pelas aulas práticas. Essas falas evidenciam pouca afinidade dos sujeitos com a disciplina, além de uma perspectiva negativa sobre o envolvimento nas atividades propostas pelos professores.

Infelizmente, a Educação Física na escola foi vista por muito tempo e ainda persiste em muitos espaços escolares como uma área do conhecimento complementar no currículo, sem muita importância, voltada apenas para a recreação dos alunos. Outro ponto relevante, percebido nos depoimentos, é a falta de motivação para participarem das atividades, tidas como práticas de Educação Física. Diversos fatores, para além da dificuldade de comunicação podem ter influenciado esse comportamento dos alunos, como relação às ações pedagógicas dos professores, que vai desde a escolha dos conteúdos, dos elementos metodológicos de ensino até a sua efetivação juntamente com os alunos. 
Em contrapartida, um dos entrevistados sinaliza uma representação positiva de sua participação nas aulas desse componente curricular, destacando o interesse e participação pelos jogos desenvolvidos, o que pode ser notado no seguinte fragmento:

$$
\text { [...] Eu gosto, é muito bom os jogos esportivos das aulas. (A7) }
$$

Segundo Bidutte (2001), as atividades que requerem maior participação, ou seja, mais movimentos, concentram maior número de motivos para aumentar o interesse e o estímulo do participante, além de despertar um sentimento de desafio. Deste modo, se durante as aulas de Educação Física o professor não priorizar atividades que possam suscitar nos alunos a motivação e o interesse, elementos tão importantes para o processo de aprendizagem, torna-se difícil que os educandos lhes deem um retorno positivo durante as aulas.

Assim, apreender que muitas vezes a predominância de modalidades esportivas durante as aulas, culturalmente, acabam excluindo, por exemplo, as alunas das atividades, mas não pelo fato de serem mulheres, mas, por serem consideradas frágeis e menos habilidosas que seus colegas homens. Além dos menos habilidosos e das mulheres, excluem-se também os gordinhos e os deficientes (DUARTE; MOURÃO, 2007).

Desse modo, é necessário que o professor, na sua ação pedagógica, esteja sempre atento a estas questões, percebendo as limitações de cada aluno, e assim desenvolva vivências corporais diversificadas que sejam prazerosas e estimuladoras, possibilitando oportunidade da interação, integração e socialização entre todos, pensando sempre em atender às individualidades dos educandos para que não haja a exclusão.

\section{Inclusão nas aulas de Educação Física}

No que se refere à inclusão nas aulas de Educação Física, apreendemos seis unidades de análise que possuem sentidos que se relacionam com a percepção dos alunos surdos sobre sua inclusão nas aulas de Educação Física, como pode ser observado nos depoimentos à seguir:

[...] o professor não tinha preocupação de despertar interesse e motivação para as aulas práticas. Os colegas ouvintes não se interessavam em me colocar no time, pois, dificultava a comunicação no jogo. Eles gritavam, eu sou surdo [...] (Al)

[...] Mais ou menos. Porque é difícil palavras de educação física $[\ldots](\mathrm{A} 2)$

A partir dessas falas, dois alunos entrevistados disseram que não se sentiam incluídos, apontando que o professor não se preocupava em incluí-lo nas aulas práticas, ocasionando desmotivação para participar, que era ampliada pela dificuldade de comunicação existente entre eles e os colegas ouvintes. 
Esse processo de inclusão requer a modificação dos sistemas sociais que compõem a sociedade de mode que não haja fatores que excluam as pessoas do seu espaço, nem afastem outras (SASSAKI, 2005). Ainda, de acordo com Palma e Lehnhard (2012), para que a inclusão aconteça, é preciso que as oportunidades sejam oferecidas a todos, independentemente de sua deficiência. Nesse sentido, a adaptação das atividades para proporcionar a participação dos alunos na aula é necessária, além de dar orientações durante as atividades e estimular a participação dos alunos, caracterizam ações que favorecem a aprendizagem e as interações entre eles (SEABRA JUNIOR, 2006).

Nesse mesmo contexto, percebe-se que as dificuldades encontradas pelos entrevistados para a efetivação desse processo estão nas estratégias educacionais que necessariamente perpassam pela questão da comunicação. Os surdos se comunicam oficialmente, através da Língua Brasileira de Sinais- LIBRAS, que é sua língua materna, contudo, no contexto escolar, é perceptível que a maioria dos professores e alunos que são ouvintes, não utilizam essa língua e poucos a conhecem, tornando difícil a comunicação entre eles. E, a partir dessa realidade, torna-se necessário repensarmos as questões inerentes à formação dos professores de Educação Física para que o atendimento a todos os alunos seja de maneira integral, não fragmentando e expondo-os a uma situação tênue às ações e práticas pedagógicas, as quais os discentes são submetidos.

Para tanto, as aulas deveriam ser desenvolvidas de maneira dinâmica e interessante, uma vez que os movimentos corporais explorados nas atividades poderão possibilitar aos alunos diversas vivências corporais, novas descobertas e assim uma ampliação do repertório motor.

Em outras unidades de sentido, notamos relatos nos quais os alunos surdos demonstram sentem-se incluídos durante o desenvolvimento das aulas de Educação Física:

[...] tenho ajuda e companhia dos colegas durantes as aulas [...] (A3)

[...] me sinto incluído quanto estou junto do meu colega que também é surdo (A4)

[...] meus colegas ouvintes me ajudam e brincamos é divertido (A6)

[...] estou sempre nas aulas, mas às vezes não gosto (A7)

O auxílio dos colegas ouvintes, durante as aulas de Educação Física, foi um aspecto bem evidenciado pelos alunos surdos, em que os mesmos afirmam que se sentem também integrados e incluídos nas atividades propostas. A partir dessa realidade, se pode argumentar que a informação sobre os resultados e consequências da interação entre alunos com surdez e seus colegas de sala pode favorecer para a diminuição de muitas análises que são feitas com base em valores discriminatórios e preconceituosos, e, dessa forma, contribuir, também, para um bom desenvolvimento das aulas. 
Portanto, o atendimento aos alunos surdos, bem como a estruturação harmoniosa do ambiente e das ações escolares podem e devem ser planejadas, dimensionadas e avaliadas para disponibilizar a todos os alunos oportunidades de interação, que, em consequência, geram elos de amizade entre eles (TEIXEIRA; KUBO, 2008). Essas interações, entre todos os alunos com ou sem deficiência são fundamentais para a concretização e materialização dos processos de uma Educação Física verdadeiramente inclusiva. Trata-se, portanto, de uma informação que merece um olhar mais suscetível, tendo em vista que as relações sociais que são estabelecidas nas aulas de Educação Física são assinaladas, muitas vezes, por uma intensidade mais acentuada, diferente da percepção em outras disciplinas, seja entre aluno-professor, seja entre aluno-aluno. Torna-se importante ponderar que essas relações não devem se findar no aspecto afetivo-emocional, muito embora essa dimensão deva ser evidenciada no processo de ensino-aprendizagem (ALMEIDA et al., 2011).

Desse modo, nota-se que muitos educadores buscam usar diversos recursos comunicativos para estabelecer um diálogo com o aluno surdo, mas nem sempre conseguem se fazer entender, o que torna o aprendizado em sala de aula mais difícil. Entretanto, em se tratando de um processo de inclusão entende-se que é necessário que a sociedade se modifique, se adequando às necessidades das pessoas com deficiência, assim o aprendizado da LIBRAS, por parte dos ouvintes, torna-se de suma importância para a concretização da inclusão educacional dos sujeitos surdos na perspectiva de uma educação de qualidade.

\section{Percepção dos alunos sobre as aulas de Educação Física}

As aulas de Educação Física, na percepção dos alunos, foram entendidas como momentos que variaram de chatos, bons a muito bons. Essas informações podem ser observadas nas unidades de análise dispostos a seguir:

[...] eu achava chato. Falava e escrevia demais o meu professor de Educação Física (A2)

[...] as aulas são boas, porque o professor ajuda e consegue responder $[\ldots](\mathrm{A} 3)$

[...]mais ou menos. Porque o surdo difícil só escrever, igual português, matemática, ciências; português difícil entender [...] (A5)

[...] muito bom a professora é muito dinâmica (A6)

[...] A professora fala pouco e escreve muito (A8)

Os entrevistados que afirmaram gostar das aulas de Educação Física deram como justificativa a forma dinâmica dos professores desenvolverem as aulas e o fato dos mesmos auxiliá-los nas atividades em sala. Ao mesmo tempo, outros revelaram suas inquietações a respeito da metodologia utilizada pelo professor da disciplina; a escrita e a fala excessiva durante as aulas tornando difícil a compreensão dos conteúdos para alunos surdos. 
Coadunando com Cidade e Freitas (2002), a metodologia utilizada pelo professor precisa estar adequada às necessidades de seus educandos dando-lhes possibilidades de desenvolver suas habilidades motoras, além da interação com os colegas e uma aprendizagem significativa dos conteúdos explorados durante as aulas. Nesse sentido, Mattos e Neira (2000) analisam que, no decorrer do período escolar, enquanto as demais áreas de estudo dedicam-se a aprofundar os conhecimentos dos alunos através de metodologias diversificadas, solução de problemas e discussão de assuntos atuais e concretos, as aulas de Educação Física limitam-se aos já conhecidos fundamentos do esporte e do jogo.

O professor de Educação Física adquire um considerável conhecimento durante sua formação, mas o empobrecimento do seu trabalho nas escolas leva-o a não utilização do que aprendeu no decorrer da sua formação profissional. A formação dos docentes frente às questões da inclusão no contexto escolar torna-se um fator decisivo para o sucesso e a materialização das leis no dia-a-dia das escolas, buscando a solidificação de uma educação verdadeiramente inclusiva, assegurando o respeito à diversidade e peculiaridade dos discentes (TERRA; GOMES, 2013). .

Do acordo Greguol et al. (2004), muitos jovens priorizam a prática esportiva nas escolas, mas isso não deveria ser motivo para o esquecimento de princípios importantes da Educação Física Escolar. Para outros autores, a Educação Física possui um papel relevante na inclusão de alunos com deficiência auditiva, no contexto regular, uma vez que, através das aulas, existe a possibilidade de se trabalhar os alunos em sua totalidade, com múltiplos objetivos, favorecendo o conhecimento do corpo, cuidado com a saúde, coordenação motora, sensibilidade e a socialização de ideias, na medida em que, compartilham-se saberes, vivencias, dificuldades e facilidades (GÓES; ALVES; JUNIOR, 2012).

Dentre os diversos fatores abordados, que são necessários para uma inclusão efetiva, a metodologia e as ações adotadas pelo professor são decisivas para a participação do aluno com deficiência nas aulas e, com isso destaca a influência da ação docente na inclusão ou distanciamento dos alunos, nas aulas de Educação Física (SEABRA JÚNIOR, 2006). Contudo, sabemos que se faz necessário que o Estado, através de políticas públicas, capacite permanentemente os professores da rede de ensino, possibilitando maior segurança e ampliação dos conhecimentos sobre as necessidades educacionais especiais.

\section{Comunicação durante as aulas}

No que se refere à comunicação, os entrevistados $\mathrm{Al}$ e $\mathrm{A} 3$ disseram que têm uma boa comunicação com seus professores; em se tratando de três professores diferentes, vale ressaltar que apenas um tinha um pouco de conhecimento sobre LIBRAS, mesmo assim, necessitam do auxilio de um intérprete; com os outros dois professores a comunicação era estabelecida, principalmente, através do intérprete de Libras, mas também por meio da leitura labial e gestos. 
[...] é complicado para nos entendermos, o professor precisa do intérprete não sabe se comunicar por Libras, mas no final tudo dá quase certo $(\mathrm{Al})$.

[...] ouvintes e surdos conversam, em Libras, gestos, vários. Eu ensinei alguns sinais porque o professor não sabe Libras, ai chama o intérprete para auxiliar (A3).

A partir das unidades de análise, entende-se que os alunos surdos buscam manter um bom diálogo, especialmente com os colegas ouvintes, que tentam se comunicar com o auxílio do intérprete, utilizando os gestos, alguns sinais de Libras que aprenderam no cotidiano com os mesmos e também através escritos. Em contrapartida, outros sujeitos da pesquisa revelam que a comunicação com seus professores era ruim e difícil:

[...] colegas e professor ajudam a colocar nos grupos, os colegas tentam se comunicar comigo através da Libras, gestos e escrevendo. Professor nunca, nada fala, quieto". (A5)

[...] minha comunicação com os colegas é melhor do que com a professora, porque eu estou todos os dias com eles e apenas em duas aulas com ela; é diferente (A6).

O entrevistado A2 relatou que tem uma boa comunicação, tanto com os colegas ouvintes quanto com o professor da disciplina, mas destaca que o diálogo estabelecido em sala de aula não fazia nenhuma referência à disciplina Educação Física.

[...] não existe a comunicação sobre a disciplina (quando conversava com o professor). Mas, durante as aulas de Educação Física era um dos horários que eu batia papo sobre outros assuntos, em Libras e muitas vezes por gestos (A2).

A partir dos depoimentos dos alunos entende-se que há tentativas, principalmente dos colegas, em estabelecer um contato e aproximação com o surdo. Além disso, os depoimentos também revelaram a importância que os alunos surdos dão à sua língua materna, como meio principal de estabelecer a comunicação entre eles e os ouvintes e o papel fundamental do intérprete de Libras nesta relação. Em todas as respostas eles enfatizaram a questão do colega ou do professor saber ou não Libras, sendo esta uma condição decisiva para garantir que os ouvintes das classes pesquisadas tenham uma boa relação e interação com os mesmos.

As Diretrizes Nacionais para Educação Especial na Educação Básica, construída em 2001 destaca e reconhece a importância da língua de sinais no acesso do aluno surdo aos conteúdos curriculares. Assim como, de acordo com a Lei $\mathrm{n}^{0}$ 10.436/02, regulamentada em abril de 2002, eles têm o direito de se comunicar por meio de sua língua comum, que é a Libras. Segundo Guarinello et al, (2012), juntamente à oficialização da LIBRAS enquanto língua da comunidade surda brasileira, há um progresso nas questões que envolvem a sistematização de ações voltadas à inclusão dos surdos no ensino regular. 
Esse movimento refletiu em mudanças no sistema educacional brasileiro as quais, por sua vez, entenderam a necessidade do ensino de LIBRAS ser ampliado para profissionais da educação, que estejam envolvidos com o desenvolvimento da linguagem vivenciados pelos surdos. Neste contexto, a Lei n ${ }^{\circ} 10.436$ (Decreto no 5.626 de 22 de dezembro de 2005), em seu artigo $4^{\circ}$ dispõe que os sistemas educacionais federal, estadual e municipal brasileiros devem garantir a inclusão de LIBRAS nos cursos de Educação Especial, de Fonoaudiologia e de Magistério, nos níveis médio e superior, como parte integrante dos Parâmetros Curriculares Nacionais. Segundo Greguol et al. (2004), a falta de conhecimento do professor em relação à língua de sinais é a maior barreira encontrada para uma efetiva participação dos alunos com deficiência auditiva nas aulas de Educação Física.

No entanto, apenas a execução de leis que tratem da inclusão não garante a eficácia e efetividade desse projeto, o que se caracteriza como apenas um impulsionador na construção subjetiva sobre esse novo panorama da inclusão (DUEK; NAUJORKS, 2007).

Por outro lado, quando o professor obtiver conhecimento da língua de sinais torna-se imprescindível que ele estabeleça sempre o diálogo e uma comunicação com seu aluno surdo, visando estabelecer uma boa relação e trocas de experiências. Este comportamento permitiria que o professor passasse a conhecer melhor o seu aluno, as suas dificuldades e necessidades educacionais, assim como criaria possibilidades de sua prática pedagógica ser mais inclusiva encontrando maneiras diferentes de desenvolver suas aulas de forma a proporcionar a compreensão, comunicação e aprendizado desses sujeitos.

\section{Considerações finais}

Os resultados da pesquisa nos mostraram que, embora a temática da inclusão esteja sendo tão difundida na sociedade e principalmente na escola, vemos que as ações voltadas para a concretização de uma aula de Educação Física, no contexto inclusivo, que atenda às necessidades dos seus educandos ainda são bastante tímidas, limitadas e ocorre de maneira parcial.

A pesquisa revelou que mesmo tendo acesso aos conteúdos da disciplina, através do auxílio do intérprete de LIBRAS em sala de aula, os alunos entrevistados demonstraram dificuldades em compreender as aulas, ressaltando que "as palavras são difíceis de entender". A dificuldade de aprendizagem que os surdos têm na aquisição da língua portuguesa escrita, demonstram ser um desafio para a maioria dos educadores que devem utilizar na sua ação pedagógica estratégias de ensino que contribuam para uma melhor assimilação e memorização dos conteúdos por parte desses sujeitos.

Diante das considerações feitas até aqui, percebe-se que a inclusão dos surdos, nas aulas de Educação Física, ainda não se efetivou de fato, mesmo existindo alguns professores com ações pedagógicas que demonstraram serem inclusivas. En- 
tende-se ser imprescindível que o professor tenha um bom relacionamento com seu aluno surdo, que ele conheça as suas dificuldades e necessidades educacionais, para que possa investir em ações pedagógicas mais inclusivas.

Por fim, destaca-se a importância de existir verdadeiras condições de acessibilidade na instituição escolar e no caso específico da Educação Física, evidencia-se a relevância do professor estar preparado para o trabalho com alunos com deficiência auditiva em todos os momentos de suas aulas, onde, de acordo Naujorks (2010), poder-se-á aumentar as possibilidades de, através das diferenças, favorecer e promover alterações de imaginários que culminem na educação inclusiva.

\section{Referências}

BRASIL. Decreto no 5.626 de 22 de dezembro de 2005. Regulamenta a Lei oㅜ 10.436, de 24 de abril de 2002 e o art. 18 da Lei no 10.098 , de 19 de dezembro de 2000, DF, 2000.

ALMEIDA, A. B. et al. Percepção discente sobre a Educação Física escolar e motivos que levam à sua prática. Revista Mackenzie de Educação Física e Esporte, v. 10, n. 2, p. 109-116, 2011.

BARDIN, L. Análise de conteúdo. Trad. Luís Antero Reto e Augusto Pinheiro. Lisboa: Edições 70, 2011.

BIDUTTE, L. C. Motivação nas aulas de Educação Física em uma escola particular. Psicologia Escolar e Educacional, v. 5, n. 2, p. 49-58, dez. 2001.

CIDADE, R. E. A.; FREITAS, P. Introdução à Educação Física e ao Desporto Adaptado para Pessoas Portadoras de Deficiência. 1. ed. Curitiba: Editora UFPR, 2002.

DIZEU, C. T. B.; CAPORALI, A. S. A Língua de Sinais constituindo o sujeito surdo. Educação e Sociedade, v. 26, n. 91, p. 583-597, mai./ago. 2005.

DUARTE, C. P.; MOURÃO, L. Representações de adolescentes femininas sobre os critérios de seleção utilizados para a participação em aulas mistas de Educação Física. Movimento, v. 13, n. 01, p. 37-56, jan./ abr. 2007.

DUEK, V. P.; NAUJORKS, M. I. Docência e inclusão: reflexões sobre a experiência de ser professor no contexto da escola inclusiva. Revista da FAEEBA - Educação e Contemporaneidade, Salvador, v. 16, n. 27, p. 1-258, jan./jun., 2007.

GÓES, F. T.; ALVES, A. C.; JUNIOR, P. R. V. Os deficientes auditivos nas aulas de Educação Física: repensando as possibilidades de atividades pedagógicas inclusivas. Revista Formação Docente, v. 4, n. 1, p. 1-16, jun. 2012.

GREGUOL, M. Natação Adaptada: Em busca do movimento com autonomia. 1. ed. Barueri: Manole, 2010.

GREGUOL, M. et al. Atitudes dos professores de Educação Física do ensino regular com relação a alunos portadores de deficiência. Revista Brasileira de Ciência e Movimento, v.12, n.2, p.63-68, jun. 2004.

GUARINELLO, A. C. et al. A disciplina de LIBRAS no contexto de formação acadêmica em Fonoaudiologia. Revista CEFAC, v. 1, p. 1-16, 2012.

MATTOS, M. G.; NEIRA, M. G. Educação física na adolescência: construindo o conhecimento na escola. 5. ed. São Paulo: Phorte, 2000. 
MATTOS, M. G.; ROSSETTO JUNIOR, A. J.; BLECHER, S. Metodologia da pesquisa em Educação Física: construindo sua monografia, artigos e projetos. 3. ed. São Paulo: Phorte, 2008.

NAUJORKS, M. I. Avaliação Educacional, inclusão escolar e representações sociais. Revista Educação Especial, v. 23, n. 38, p. 399-408, set./dez. 2010

NOZI, G. S.; VITALIANO, C. R. Saberes necessários aos professores para promover a inclusão de alunos com necessidades Educacionais Especiais. Revista Educação Especial, v. 25, n. 43, p. 333-348, mai./ago. 2012.

PALMA, L. E.; LENHARD, G. R. Aulas de Educação Física e inclusão: um estudo de caso com a deficiência física. Revista Educação Especial, v. 25, n. 42, p. 115-126, jan./abr. 2012

RECHINELI, A.; PORTO, E. T. R.; MOREIRA, T. R. Corpos deficientes, eficientes e diferentes: uma visão a partir da Educação Física. Revista Brasileira de Educação Especial, v. 14, n. 2, p. 293-310, mai./ago. 2008.

SANTOS FILHO, J. C.; GAMBOA, S. S. Pesquisa Educacional: quantidade-qualidade. 6. ed. São Paulo: Cortez, 2007.

SASSAKI, R. K. Inclusão: o paradigma do século 21. Inclusão - Revista da Educação Especial, n. 1, p. 19-23, out. 2005

SEABRA JÚNIOR, L. Inclusão, necessidades especiais e Educação Física: considerações sobre a ação pedagógica no ambiente escolar. Dissertação (Mestrado) - Faculdade de Educação Física, Universidade Estadual de Campinas, Campinas, 2006.

TEIXEIRA, F. C.; KUBO, O. M. Características das interações entre alunos com Síndrome de Down e seus colegas de turma no sistema regular de ensino. Revista Brasileira de Educação Especial, v. 14, n. 1, p. 75 92, jan./abr. 2008.

TERRA, R. N.; GOMES, C. G. Inclusão escolar: carências e desafios na formação e atuação profissional. Revista Educação Especial, v. 26, n. 45, p. 109-124, jan./abr. 2013.

VILELA-RIBEIRO, E. M.; BENEDITE, A. M. C; VILELA, E. B. Sala de aula e diversidade. Revista Educação Especial, v. 26, n. 45, p. 145-160, jan./abr. 2013.

\section{Correspondência}

Tássia Pereira Alves - Universidade Estadual do Sudoeste da Bahia, Avenida José Moreira Sobrinho, CEP: 45214-999, Jequié, Bahia, Brasil.

E-mail: tassinha29@hotmail.com - zenysalles@gmail.com - ramonefisica@hotmail.com - leoduarteef@ hotmail.com - rianeefelix@hotmail.com

Recebido em 27 de fevereiro de 2013

Aprovado em 03 de julho de 2013 
